\title{
HUBUNGAN TINGKAT PENGETAHUAN DAN PERILAKU PEMBUDIDAYA TANAMAN HIAS TERHADAP KONTAMINASI TANAH OLEH SOIL TRANSMITTED HELMINTHS DI DESA KOTAGAJAH
}

\author{
Ade Tia Ningrum ${ }^{1}$, Eka Sulistianingsih ${ }^{1}$, Marhamah $^{1}$ \\ ${ }^{1}$ Program Studi Teknologi Laboratorium Medis Program Sarjana Terapan \\ Jurusan Analis Kesehatan Politeknik Kesehatan Tanjungkarang \\ [email korespondensi: adetianingrum02@gmail.com]
}

\begin{abstract}
Correlation Between Knowledge and Behavior of Ornamental Plant Cultivators to Soil Contamination by Soil Transmitted Helminths in Kotagajah. Based on World Health Organization data, more than 1.5 billion people or $24 \%$ of the world population are infected by soil transmitted helminths. Soil can be contaminated with worm eggs released with feces from an infected person. Knowledge and behavior are factors that play a role in the spread of soil transmitted helminths infections. The purpose of this study was to determine the percentage of soil contaminated with soil transmitted helminths eggs, to determine the level of knowledge and behavior of ornamental plant cultivators (defecation habits, waste management methods, and liquid waste management methods), to determine the correlation between the level of knowledge and behavior of ornamental plant cultivators with soil contamination by soil transmitted helminths. This type of research is analytic by using a cross sectional study design. The results showed that the percentage of soil contaminated with soil transmitted helminth eggs was $8(26.7 \%)$. There is a correlation between the level of knowledge and soil contamination by soil transmitted helminths ( $p$ value 0.009$)$. There is a correlation between defecation habits and soil contamination by soil transmitted helminths ( $p$ value 0.002 ), there is no correlation between waste management methods and soil contamination by soil transmitted helminths ( $p$ value 0.284 ), and there is no correlation between wastewater management methods and soil contamination by soil transmitted helminths ( $p$ value 0.060).
\end{abstract}

Keywords: Soil Contamination, Knowledge, Behavior, Soil Transmitted Helminths

\begin{abstract}
Abstrak: Hubungan Tingkat Pengetahuan Dan Perilaku Pembudidaya Tanaman Hias Terhadap Kontaminasi Tanah Oleh Soil Transmitted Helminths Di Desa Kotagajah. World Health Organization menyebutkan lebih dari 1,5 miliar orang atau $24 \%$ penduduk dunia terinfeksi cacing yang ditularkan melalui tanah atau soil transmitted helminths. Tanah dapat terkontaminasi telur cacing yang dikeluarkan bersama tinja oleh orang yang terinfeksi. Pengetahuan dan perilaku merupakan faktor yang berperan dalam penyebaran infeksi soil transmitted helminths. Tujuan dari penelitian ini yaitu mengetahui persentase tanah yang terkontaminasi telur soil transmitted helminths, mengetahui tingkat pengetahuan dan perilaku pembudidaya tanaman hias (kebiasaan buang air besar, cara pengelolaan sampah, dan cara pengelolaan limbah cair), mengetahui hubungan tingkat pengetahuan dan perilaku pembudidaya tanaman hias dengan kontaminasi tanah oleh soil transmitted helminths. Jenis penelitian ini adalah analitik dengan menggunakan desain studi cross sectional. Hasil penelitian didapatkan persentase tanah yang terkontaminasi telur soil transmitted helminths sebanyak $8(26,7 \%)$. Terdapat hubungan antara tingkat pengetahuan dengan kontaminasi tanah oleh soil transmitted helminths ( $p$ value 0,009). Terdapat hubungan kebiasaan buang air besar dengan kontaminasi tanah oleh soil transmitted helminths ( $p$ value 0,002), tidak ada hubungan antara cara pengelolaan sampah dengan kontaminasi tanah oleh soil transmitted helminths ( $p$
\end{abstract}


value 0,284), dan tidak ada hubungan cara pengelolaan limbah cair dengan kontaminasi tanah oleh soil transmitted helminths ( $p$ value 0,060$)$.

Kata Kunci: Kontaminasi Tanah, Pengetahuan, Perilaku, Soil Transmitted Helminths

\section{PENDAHULUAN}

Infeksi yang disebabkan oleh soil transmitted helminths merupakan salah satu masalah kesehatan yang masih banyak ditemukan di dunia terutama tersebar di daerah tropis dan subtropis salah satunya Indonesia. Spesies soil transmitted helminths yang menginfeksi manusia adalah cacing gelang (Ascaris lumbricoides), cacing cambuk (Trichuris trichiura), dan cacing tambang (Necator americanus dan Ancylostoma duodenale) (WHO, 2020).

Berdasarkan data dari World Health Organization 2020 lebih dari 1,5 miliar orang atau $24 \%$ penduduk dunia terinfeksi soil transmitted helminths. Kasus dengan jumlah terbesar terjadi di wilayah sub-Sahara Afrika, Amerika, Cina, dan Asia Timur. Sebanyak $70 \%$ penduduk Asia terinfeksi soil transmitted helminths dengan prevalensi di Asia Tenggara yaitu sebesar 14-23\% terinfeksi Ascaris lumbricoides, 9-19\% terinfeksi Trichuris trichiura, dan 9-15\% terinfeksi cacing tambang (Necator americanus dan Ancylostoma duodenale) (Silver, 2018). Sementara itu, prevalensi penyakit kecacingan akibat soil transmitted helminths di Indonesia juga tergolong tinggi, terutama pada golongan penduduk yang kurang mampu dengan sanitasi yang buruk yaitu berkisar antara 2,5\%-62\% (Permenkes, 2017).

Pengetahuan dan perilaku merupakan faktor yang berperan dalam penyebaran infeksi soil transmitted helminths. Perilaku yang baik dapat mengurangi risiko terkena penyakit. Perilaku seseorang dapat tumbuh dipengaruhi oleh pengetahuan yang diperoleh dari pengalaman, sehingga hal tersebut dapat memunculkan sikap dan tindakan terhadap nilai-nilai yang baik, salah satunya adalah nilai kesehatan. Kurangnya pengetahuan tentang infeksi soil transmitted helminths merupakan faktor dasar seseorang berperilaku, salah satunya tidak menerapkan personal hygiene dengan baik (Rahmayanti, 2014). Penelitian yang dilakukan oleh Oyebamiji (2018) di Ibadan, Nigeria menyebutkan bahwa tingginya prevalensi kontaminasi tanah dan tingginya proporsi masyarakat dengan pengetahuan yang kurang memadai tentang cara pencegahan penularan soil transmitted helminths dapat menimbulkan risiko tinggi seseorang untuk terinfeksi parasit ini.

Tanah merupakan media penting untuk pertumbuhan dan siklus hidup soil transmitted helminths. Kondisi yang baik untuk pertumbuhan telur cacing menjadi bentuk infektif adalah tanah yang lembab dan cukup teduh dengan suhu optimum $25^{\circ}-30^{\circ} \mathrm{C}$ untuk Ascaris lumbricoides, $30^{\circ} \mathrm{C}$ untuk Trichuris trichiura, dan $23^{\circ}-33^{\circ} \mathrm{C}$ untuk cacing tambang (Necator americanus dan Ancylostoma duodenale) (Sutanto, 2008).

Tinggi rendahnya frekuensi penularan penyakit yang disebabkan oleh soil transmitted helminths berhubungan erat dengan terkontaminasinya tanah oleh tinja yang mengandung telur soil transmitted helminths (Samad, 2009). Kebiasaan buang air besar di tanah yang dilakukan oleh seseorang yang terinfeksi soil transmitted helminths merupakan salah satu penyebab tanah menjadi terkontaminasi oleh telur cacing, selain itu pengelolaan sampah dan limbah cair (buangan kamar mandi, dapur, dan air cuci pakaian) yang tidak tepat yaitu dibuang sembarang tempat sekitar rumah membuat kondisi tanah menjadi selalu basah dan lembab sehingga mendukung perkembangan soil transmitted helminths dalam tanah (Syavira, 2018). Sesuai dengan penelitian yang dilakukan oleh Sumanto (2012) yaitu kebiasaan buang air besar di tanah dan pengelolaan limbah cair di pekarangan rumah berhubungan dengan paparan soil transmitted helminths. 
Semakin banyak telur soil transmitted helminths yang ditemukan pada sumber kontaminasi seperti tanah, maka semakin tinggi derajat endemi penyakit kecacingan di suatu daerah dengan infeksi yang semakin berat (Lestari, 2014). Berdasarkan penelitian yang dilakukan oleh Juhairiyah dkk (2020) mengenai kontaminasi telur dan larva cacing usus pada tanah di Desa Juku Eja Kabupaten Tanah Bumbu, ditemukan larva cacing tambang pada lingkungan sekolah dan telur cacing Trichuris trichiura di sekitar rumah penderita positif kecacingan, sehingga kontaminasi tanah oleh telur dan larva cacing dapat menjadi sumber risiko penularan infeksi soil transmitted helminths, jika terjadi kontak dengan tanah tanpa menggunakan pelindung diri seperti sarung tangan dan alas kaki. Penelitian lainnya dilakukan oleh Samad (2009) di kota Medan memperlihatkan bahwa persentase kontaminasi telur soil transmitted helminths pada 80 sampel tanah yang diteliti yaitu sebesar 52,5 $\%$.

Budidaya tanaman hias merupakan salah satu kegiatan yang berhubungan langsung dengan tanah sehingga berisiko terinfeksi soil transmitted helminths (Damayanti, 2006). Hal tersebut sejalan dengan penelitian Siregar dkk (2013) di Pekanbaru menunjukkan sebesar $77,8 \%$ pekerja tanaman yang diperiksa terinfeksi soil transmitted helminths. Penelitian lain dilakukan oleh Inayati dkk (2015) mengenai infeksi cacing soil transmitted helminths pada penjual tanaman hias di Bintaro didapatkan hasil sebanyak $21,42 \%$ penjual tanaman hias terinfeksi parasit tersebut.

Kotagajah merupakan salah satu Desa yang terletak di Kecamatan Kotagajah Kabupaten Lampung Tengah dengan luas wilayah $68.05 \mathrm{~km}^{2}$. Menurut Data Badan Meteorologi Klimatologi dan Geofisika di Provinsi Lampung menunjukan bahwa temperatur Kecamatan Kotagajah Kabupaten Lampung Tengah berada pada kisaran $20^{\circ}-31^{\circ} \mathrm{C}$ serta memiliki kelembaban udara berkisar 80-88\%. Berdasarkan hasil observasi yang telah dilakukan, ditemukan sebanyak 30 masyarakat di Desa Kotagajah yang memiliki kegemaran membudidaya tanaman hias. Masyarakat tersebut menggunakan tanah sebagai media tanam yang didapatkan dari pekarangan rumah dan pupuk kandang sebagai media penyubur tanaman hias yang didapatkan dari hewan ternak.

Berdasarkan latar belakang tersebut maka peneliti bertujuan untuk melakukan penelitian mengenai "Hubungan Tingkat Pengetahuan dan Perilaku Pembudidaya Tanaman Hias Terhadap Kontaminasi Tanah oleh Soil Transmitted Helminths di Desa Kotagajah"

\section{METODE}

Jenis penelitian yang digunakan adalah analitik dengan menggunakan desain studi cross sectional. Variabel dalam penelitian ini meliputi variabel bebas yaitu tingkat pengetahuan dan perilaku pembudidaya tanaman hias, sedangkan variabel terikat yaitu kontaminasi tanah oleh soil transmitted helminths. Populasi pada penelitian ini adalah pembudidaya tanaman hias dan media tanah tanaman hias di Desa Kotagajah. Sampel pada penelitian ini yaitu 30 pembudidaya tanaman hias sebagai responden dan 30 tanah yang digunakan pembudidaya tanaman hias sebagai media tanam. Penelitian dilaksanakan pada April-Mei 2021. Identifikasi telur soil transmitted helminths pada media tanah tanaman hias dilakukan di laboratorium Parasitologi Jurusan Analis Kesehatan Politeknik Kesehatan Tanjungkarang. Analisis data yang digunakan yaitu analisis univariat untuk mengetahui persentase tanah yang terkontaminasi telur soil transmitted helminths, tingkat pengetahuan, perilaku pembudidaya tanaman hias, dan analisis bivariat menggunakan uji chi square.

\section{HASIL}

Penelitian mengenai hubungan tingkat pengetahuan dan perilaku pembudidaya tanaman hias terhadap kontaminasi tanah oleh soil transmitted helminths di Desa Kotagajah telah dilaksanakan pada April-Mei 2021. 
Pemeriksaan tanah dilakukan di Laboratorium Parasitologi Jurusan Analis Kesehatan Politeknik Kesehatan
Tanjungkarang, jumlah sampel yang diperiksa sebanyak 30 dan diperoleh hasil sebagai berikut:

Tabel 1. Persentase Tanah Pembudidaya Tanaman Hias Di Desa Kotagajah Yang Terkontaminasi Telur Soil Transmitted Helminths

\begin{tabular}{cccc}
\hline No & Hasil Identifikasi & Frekuensi (N) & $\begin{array}{c}\text { Persentase } \\
(\mathbf{\%})\end{array}$ \\
\hline 1. & Terkontaminasi & 8 & 26,7 \\
2. & Tidak Terkontaminasi & 22 & 73,3 \\
\hline & Total & $\mathbf{3 0}$ & $\mathbf{1 0 0}$
\end{tabular}

Berdasarkan tabel 1 didapatkan data bahwa tanah yang terkontaminasi soil transmitted helminths sebanyak 8
$(26,7 \%)$ dan tidak terkontaminasi sebanyak $22(73,3 \%)$.

Tabel 2. Persentase Tingkat Pengetahuan Pembudidaya Tanaman Hias Di Desa Kotagajah Mengenai Soil Transmitted Helminths

\begin{tabular}{|c|c|c|c|}
\hline No & Kategori & Frekuensi (N) & Persentase (\%) \\
\hline 1. & Baik & 17 & 56,7 \\
\hline 2. & Kurang Baik & 13 & 43,3 \\
\hline & Total & 30 & 100 \\
\hline
\end{tabular}

Berdasarkan tabel 2 didapatkan hasil sebanyak $17(56,7 \%)$ mempunyai pengetahuan yang baik dan $13(43,3 \%)$ mempunyai pengetahuan yang kurang baik mengenai soil transmitted helminths.

Tabel 3. Persentase Perilaku Pembudidaya Tanaman Hias (Kebiasaan Buang Air Besar, Cara Pengelolaan Sampah, Dan Cara Pengelolaan Limbah Cair) Di Desa Kotagajah

\begin{tabular}{clcc}
\hline No & \multicolumn{1}{c}{ Kategori } & $\begin{array}{c}\text { Frekuensi } \\
(\mathbf{N})\end{array}$ & Persentase (\%) \\
\hline 1. Kebiasaan buang air besar & 24 & 80 \\
& I Jamban & 6 & 20 \\
I Jamban dan kebun & 26 & 86,7 \\
2. Cara pengelolaan sampah & 4 & 13,3 \\
& I Dibakar/ditimbun/ditampung & & \\
I Dibuang sembarang di kebun & 23 & 76,7 \\
3. Cara pengelolaan limbah cair & 7 & 23,3 \\
&
\end{tabular}

Berdasarkan tabel 3 diperoleh hasil bahwa $24(80 \%)$ pembudidaya tanaman hias memiliki kebiasaan buang air besar di jamban dan 6 (20\%) memiliki kebiasaan buang air besar di jamban dan kebun. Tabel tersebut juga menunjukkan $26(86,7 \%)$ pembudidaya tanaman hias memiliki perilaku yang baik dalam pengelolaan sampah, yaitu dengan melakukan pembakaran, penimbunan atau ditampung pada tempat khusus. $4(13,3 \%)$ mengelola sampah dengan cara dibuang sembarangan di kebun. Pengelolaan limbah cair didapatkan hasil bahwa 23 $(76,7 \%)$ pembudidaya tanaman hias mengelola limbah cair dengan cara mengalirkan ke selokan, 7 (23,3\%) dengan mengalirkan ke sembarang tempat. 
Tabel 4. Hubungan tingkat pengetahuan pembudidaya tanaman hias dengan kontaminasi tanah oleh soil transmitted helminths di Desa Kotagajah

\begin{tabular}{llccc}
\hline \multirow{2}{*}{$\begin{array}{c}\text { Tingkat } \\
\text { Pengetahuan }\end{array}$} & \multicolumn{3}{c}{ Kontaminasi tanah oleh } \\
\cline { 2 - 4 } & telur soil transmitted helminths & \multirow{2}{*}{ Terkontaminasi value } \\
\cline { 2 - 4 } & \multicolumn{1}{c}{$\begin{array}{c}\text { Tidak } \\
\text { Terkontaminasi }\end{array}$} & Total & \\
\hline Baik & 1 & 16 & 17 & 0,009 \\
Kurang Baik & 7 & 6 & 13 & \\
\hline
\end{tabular}

Hasil dari analisa bivariat pada tabel 4 menunjukkan adanya hubungan antara tingkat pengetahuan pembudidaya tanaman hias dengan kontaminasi tanah oleh soil transmitted helminths ( $p$ value $<0,05)$.

Tabel 5. Hubungan Perilaku Pembudidaya Tanaman Hias Dengan Kontaminasi Tanah Oleh Soil Transmitted Helminths Di Desa Kotagajah

\begin{tabular}{|c|c|c|c|c|c|}
\hline \multirow[t]{2}{*}{ No } & \multirow[t]{2}{*}{ Perilaku } & \multicolumn{3}{|c|}{$\begin{array}{c}\text { Kontaminasi tanah oleh } \\
\text { telur soil transmitted helminths }\end{array}$} & \multirow{2}{*}{$\begin{array}{c}p \\
\text { value }\end{array}$} \\
\hline & & Terkontaminasi & $\begin{array}{c}\text { Tidak } \\
\text { Terkontaminasi }\end{array}$ & Total & \\
\hline & $\begin{array}{l}\text { Kebiasaan buang air besar } \\
\text { Jamban } \\
\text { Jamban dan kebun }\end{array}$ & $\begin{array}{l}3 \\
4\end{array}$ & $\begin{array}{c}21 \\
1\end{array}$ & $\begin{array}{l}24 \\
6\end{array}$ & 0,002 \\
\hline 2. & Cara pengelolaan sampah & & & & \\
\hline & $\begin{array}{l}\text { Dibakar/ditimbun/ditampung } \\
\text { Dibuang sembarang di kebun }\end{array}$ & $\begin{array}{l}6 \\
2\end{array}$ & $\begin{array}{c}20 \\
2\end{array}$ & $\begin{array}{l}26 \\
4\end{array}$ & 0,284 \\
\hline 3. & $\begin{array}{l}\text { Cara pengelolaan limbah cair } \\
\text { Dialirkan ke selokan } \\
\text { Mengalir ke sembarang tempat }\end{array}$ & $\begin{array}{l}4 \\
4\end{array}$ & $\begin{array}{c}19 \\
3\end{array}$ & $\begin{array}{l}23 \\
7\end{array}$ & 0,060 \\
\hline
\end{tabular}

Berdasarkan tabel 5 didapatkan hasil bahwa kebiasaan buang air besar berhubungan dengan kontaminasi tanah oleh soil transmitted helminths dengan $p$ value $<0,05$ sedangkan cara pengelolaan sampah dan cara pengelolaan limbah cair tidak berhubungan dengan kontaminasi tanah oleh soil transmitted helminths dengan $p$ value $>0,05$.

\section{PEMBAHASAN}

Berdasarkan hasil pemeriksaan soil transmitted helminths pada tanah pembudidaya tanaman hias di Desa Kotagajah, didapatkan sebanyak 8 $(26,7 \%)$ tanah terkontaminasi telur soil transmitted helminths. Dapat diketahui dari tabel 3, bahwa 6 (20\%) pembudidaya tanaman hias masih buang air besar di jamban dan kebun.

Adanya telur cacing pada tinja penderita yang melakukan aktifitas buang air besar di tanah terbuka, seperti kebun akan memperbesar peluang kontaminasi tanah oleh soil transmitted helminths. Perilaku tersebut dapat menjadi faktor risiko penyebaran soil transmitted helminths di tanah, sebab cacing ini memerlukan media tanah dalam proses pematangan telur menjadi bentuk infektif.

Hasil pemeriksaan tanah didapatkan spesies soil transmitted helminths yang mengkontaminasi media tanah pembudidaya tanaman hias yaitu Ascaris lumbricoides. Hal ini disebabkan telur Ascaris lumbricoides memiliki lapisan vitelin (lipid) yang cukup tebal sehingga tahan terhadap desinfektan dan juga suasana ekstrim seperti asam, basa, dan temperatur rendah (dapat bertahan hingga suhu kurang dari $8^{\circ} \mathrm{C}$ ) dan telur dapat hidup berbulan-bulan di dalam air selokan dan tinja, sehingga kontaminasi tanah akibat Ascaris lumbricoides cenderung lebih dominan. Sejalan dengan 
penelitian Nurjana dkk (2012) di Donggala menyatakan bahwa spesies soil transmitted helminths yang banyak menginfeksi adalah Ascaris lumbricoides.

Pengetahuan mengenai soil transmitted helminths khususnya cara penularan dan pencegahan cacing ini sangat penting diketahui oleh masyarakat, terutama pada pekerja yang berhubungan langsung dengan tanah, sebagai upaya mengurangi kontaminasi tanah oleh soil transmitted helminths. Dapat diketahui dari tabel 4, bahwa persentase terbesar tanah yang terkontaminasi soil transmitted helminths terletak pada pembudidaya tanaman hias yang memiliki tingkat pengetahuan kurang baik. Kurangnya pengetahuan mengenai soil transmitted helminths disebabkan masih sedikitnya informasi yang diperoleh pembudidaya tanaman hias mengenai cacing ini. Berdasarkan hasil pengisian kuesioner, $16(53 \%)$ pembudidaya tanaman hias tidak pernah mendapat informasi mengenai soil transmitted helminths.

Hal ini disebabkan masih kurangnya penyuluhan kesehatan khususnya mengenai soil transmitted helminths bagi pembudidaya tanaman hias, sehingga penyuluhan kesehatan sangat penting dilakukan kepada pembudidaya tanaman hias sebagai upaya mengurangi penyebaran soil transmitted helminths. Sesuai dengan penelitian Rahmayanti dkk (2014) di Aceh, yang menjelaskan bahwa informasi akan memberikan pengaruh pada tingkat pengetahuan seseorang, sehingga semakin banyak informasi yang diperoleh semakin banyak pula pengetahuan yang didapat tentang kesehatan.

Hasil analisa bivariat antara tingkat pengetahuan pembudidaya tanaman hias dengan kontaminasi tanah oleh soil transmitted helminths diperoleh $p$ value 0,009 ( $p$ value < $0,05)$, artinya ada hubungan antara tingkat pengetahuan pembudidaya tanaman hias dengan kontaminasi tanah oleh soil transmitted helminths. Semakin baik tingkat pengetahuan pembudidaya tanaman hias, maka semakin rendah angka kontaminasi tanah oleh soil transmitted helminths. Jadi, pengetahuan merupakan salah satu aspek yang berpengaruh terhadap penyebaran soil transmitted helminths. Pembudidaya tanaman hias yang memiliki pengetahuan baik mengenai soil transmitted helminths diharapkan menerapkan perilaku yang baik untuk mencegah penyebaran soil transmitted helminths, salah satunya dengan buang air besar di jamban.

Berdasarkan

perilaku pembudidaya tanaman hias khususnya kebiasaan buang air besar pada tabel 5 , diketahui $5 \quad(62,5 \%)$ tanah yang terkontaminasi soil transmitted helminths berasal dari pembudidaya tanaman hias yang memiliki kebiasaan buang air besar di jamban dan kebun, sedangkan $3(37,5 \%)$ tanah yang terkontaminasi soil transmitted helminths berasal dari pembudidaya tanaman hias yang memiliki kebiasaan buang air besar hanya di jamban. Hasil analisa bivariat antara kebiasaan buang air besar pembudidaya tanaman hias dengan kontaminasi tanah oleh soil transmitted helminths didapatkan hasil $p$ value 0,002, artinya ada hubungan antara kebiasaan buang air besar pembudidaya tanaman hias dengan kontaminasi tanah oleh soil transmitted helminths. Adanya hubungan kebiasaan buang air besar dengan kontaminasi tanah oleh soil transmitted helminths diindikasi karena tinja memiliki peranan yang besar dalam penyebaran soil transmitted helminths. Apabila pembuangan tinja bukan di jamban, maka dapat menyebabkan terjadinya kontaminasi tanah yang merupakan media perkembangan soil transmitted helminths. Hal serupa disampaikan oleh Sumanto (2012) dalam penelitiannya di Desa Rejosari, Demak yang menjelaskan bahwa terdapat hubungan yang sangat signifikan antara paparan salah satu spesies soil transmitted helminths yaitu telur cacing tambang pada tanah dengan kebiasaan buang air besar.

Berdasarkan perilaku pembudidaya tanaman hias khususnya cara pengelolaan sampah pada tabel 3, $26(86,7 \%)$ pembudidaya tanaman hias mengelola sampah dengan cara dibakar, 
ditimbun, dan ditampung pada tempat khusus pembuangan sampah. Sampah rumah tangga khususnya sampah organik dimanfaatkan pembudidaya sebagai pupuk tanaman hias. Tabel 5 menunjukkan bahwa 6 (75\%) tanah yang terkontaminasi soil transmitted helminths berasal dari pembudidaya tanaman hias pengelolaan sampahnya sudah baik. Hasil analisa bivariat antara cara pengelolaan sampah dengan kontaminasi tanah oleh soil transmitted helminths didapatkan hasil $p$ value 0,284 ( $p$ value $>0,05$ ), sehingga tidak ada hubungan antara cara pengelolaan sampah dengan kontaminasi tanah oleh soil transmitted helminths. $\mathrm{Hal}$ ini disebabkan sebagian besar pembudidaya tanaman hias sudah mengelola sampah dengan baik dan tanah di area pembuangan sampah tidak terpapar aktivitas buang air besar, sebab berdasarkan siklus hidupnya faktor yang lebih utama adalah adanya aktivitas buang air besar di tanah terbuka oleh orang yang terinfeksi soil transmitted helminths. Pembudidaya tanaman hias yang sudah terinfeksi dapat mengeluarkan tinja yang berisi telur yang telah dibuahi dan apabila buang air besar di tanah terbuka, maka telur akan mengkontaminasi tanah.

Perilaku pembudidaya tanaman hias yaitu cara pengelolaan limbah cair tergolong cukup baik. Hasil penelitian diperoleh $23(76,7 \%)$ pembudidaya tanaman hias mengalirkan limbah cair ke saluran pembuangan air limbah, namun masih ditemui sarana pembuangan limbah cair yang salurannya tidak lancar serta berbau. Limbah cair tersebut berasal dari air kamar mandi, tempat cuci, dan dapur. Menurut Gazali dkk (2018) air limbah yang tidak dikelola atau dibuang di tanah terbuka sangat berbahaya terhadap kesehatan manusia, mengingat banyak penyakit yang dapat ditularkan melalui air limbah. Tabel 5 menunjukkan 4 (50\%) tanah yang terkontaminasi soil transmitted helminths berasal dari pembudidaya tanaman hias yang tidak mengelola limbah cair dengan baik. Hasil analisa bivariat antara cara pengelolaan limbah cair dengan kontaminasi tanah oleh soil transmitted helminths diperoleh $p$ value 0,060 , angka tersebut menunjukan hasil yang tidak signifikan ( $p$ value $>0,05$ ) sehingga tidak ada hubungan antara cara pengelolaan limbah cair dengan kontaminasi tanah oleh soil transmitted helminths. Hal ini disebabkan, sebagian besar tanah di area pembuangan limbah cair tidak terpapar aktivitas buang air orang yang terinfeksi soil transmitted helminths.

\section{KESIMPULAN}

Berdasarkan hasil penelitian yang telah dilakukan mengenai hubungan tingkat pengetahuan dan perilaku pembudidaya tanaman hias terhadap kontaminasi tanah oleh soil transmitted helminths di Desa Kotagajah, dapat disimpulkan bahwa Persentase tanah yang terkontaminasi oleh soil transmitted helminths yaitu sebesar $26,7 \%$.

Tingkat pengetahuan pembudidaya tanaman hias mengenai soil transmitted helminths dengan kategori baik sebanyak $17(56,7 \%)$ dan kategori kurang baik sebanyak 13 $(43,3 \%)$.

Pembudidaya tanaman hias yang memiliki perilaku baik dalam buang air besar di jamban sebanyak 24 (80\%) dan $6(20 \%)$ buang air besar di jamban dan kebun. Sebanyak $26 \quad(86,7 \%)$ pembudidaya tanaman hias memiliki perilaku yang baik dalam pengelolaan sampah, yaitu dengan melakukan pembakaran, penimbunan atau ditampung pada tempat khusus dan 4 $(13,3 \%)$ mengelola sampah dengan cara dibuang sembarangan di kebun. Sebanyak $23(76,7 \%)$ pembudidaya tanaman hias memiliki perilaku yang baik dalam pengelolaan limbah cair dengan cara mengalirkan ke selokan dan $7(23,3 \%)$ mengelola limbah cair dengan cara mengalirkan ke sembarang tempat.

Terdapat hubungan antara tingkat pengetahuan pembudidaya tanaman hias dengan kontaminasi tanah oleh soil transmitted helminths dengan $p$ value 0,009 .

Terdapat hubungan perilaku pembudidaya tanaman hias yaitu kebiasaan buang air besar dengan 
kontaminasi tanah oleh soil transmitted helminths ( $p$ value 0,002), tidak ada hubungan antara cara pengelolaan sampah ( $p$ value 0,284$)$ dan pengelolaan limbah cair ( $p$ value 0,060 ) dengan kontaminasi tanah oleh soil transmitted helminths.

\section{SARAN}

Berdasarkan simpulan hasil penelitian maka peneliti memberikan saran untuk melakukan penelitian mengenai identifikasi soil transmitted helminths pada tinja pembudidaya tanaman hias di Desa Kotagajah.

\section{DAFTAR PUSTAKA}

Damayanti, P.A.S., Laksmi, D.A. (2006). Prevalensi Soil Transmitted Helminths pada Pekerja Tanaman Hias di Kelurahan Renon, Denpasar Tahun 2006, Fakultas Kedokteran, Universitas Udayana, Bali.

Gazali, M., Marwanto, A., Rahmawati, U. (2018). Pelaksanaan Sanitasi Total Berbasis Masyarakat (STBM) Terhadap Kejadian Infeksi Kecacingan pada Pekerja Penyadap Karet. Journal of Nursing and Public Health 6(2).

Inayati, N., Tatontos, E.Y., Fihiruddin. (2015). Infeksi Cacing Soil Transmitted Helminths pada Penjual Tanaman Hias di Bintaro Kota Mataram. Jurnal Penelitian 9(4).

Juhairiyah, Indriyati, L., Hairani, B., Fakhrizal, D. (2020). Kontaminasi Telur Dan Larva Cacing Usus Pada Tanah di Desa Juku Eja Kabupaten Tanah Bumbu. Jurnal Kesehatan Lingkungan Indonesia, Balai Litbangkes Tanah Bumbu, Badan Litbang Kesehatan, Kalimantan Selatan.

Lestari, Titi Widya. (2014). Hubungan Tingkat Pengetahuan, Sikap dan Perilaku Pencegahan Kecacingan dengan Status Kecacingan Siswa SDN 03 Pontianak Timur Kotamadya Pontianak Tahun 2014. [Naskah Publikasi]. Pontianak: Fakultas Kedokteran, Universitas Tanjungpura, Pontianak.
Nurjana, M.A., Samarang, Sumolang, P.P.F., Gunawan. (2012). Pengetahuan dan Perilaku Anak Sekolah Tentang Kecacingan di Beberapa Sekolah Dasar di Kecamatan Labuan Kabupaten Donggala Tahun 2012. Jurnal Vektor Penyakit 6(1).

Oyebamiji D.A., Ebisike, A.N., Egede, J.O., Hassan, A.A. (2018). Knowledge, attitude and practice with respect to soil contamination by Soil-Transmitted Helminths in Ibadan, Southwestern Nigeria. Journal Research, Parasitology Unit, Department of Zoology, Faculty of Science, University of Ibadan, Oyo State, Nigeria.

Peraturan Menteri Kesehatan Republik Indonesia Nomor 15 Tahun 2017 Tentang Cacingan. Penanggulangan

Rahmayanti, Razali, Mudatsir. (2014). Hubungan Pengetahuan, Sikap dan Tindakan dengan Infeksi Soil Transmitted Helminths (STH) Pada Murid Kelas 1, 2 dan 3 SDN Pertiwi Lamgarot Kecamatan Ingin Jaya Kabupaten Aceh Besar. Jurnal Biotik 2(2).

Samad, H. (2009). Hubungan Infeksi dengan Pencemaran Tanah Oleh Telur Cacing yang ditularkan Melalui Tanah dan Perilaku Anak Sekolah Dasar di Kelurahan Tembung Kecamatan Medan Tembung. [Tesis]. Sumatera Utara: Sekolah Pascasarjana, Universitas Sumatera Utara.

Silver Z.A., Saravanakumar, Kaliappan, Samuel, P., Venugopal, S.,Kang, G., Sarkar., R., Ajjampur, S.R.R. (2018). Geographical distribution of Soil transmitted helminths and The Effects of Community Type in South Asia and Southeast Asia \pm A Systematic Review. Research Article, PLOS Neglected Tropical Diseases.

Siregar, I., Zulkarnain, Anita, S. (2013). Hubungan Personal Hygiene dengan Penyakit Cacing (Soil Transmitted Helminth) pada Pekerja Tanaman Kota Pekanbaru. Jurnal Penelitian, Pusat Penelitian 
Lingkungan Hidup Universitas Riau.

Sumanto, Didik. (2012). Uji Paparan Telur Cacing Tambang pada Tanah Halaman Rumah. Jurnal Penelitian, Fakultas IImu Keperawatan dan Kesehatan, Universitas Muhammadiyah Semarang, Jawa Tengah.

Sutanto, I., Ismid, I.S., Sjarifuddin, P.K., Sungkar, S. (2008). Buku Ajar Parasitologi Kedokteran Edisi Keempat, Fakultas Kedokteran Universitas Indonesia, Jakarta Keempat. Jakarta: Fakultas Kedokteran Universitas Indonesia.

Syavira, N.A., (2018). Identifikasi Pencemaran Tanah oleh Telur dan Larva Soil Transmitted Helminths di Desa Klungkung Kecamatan Sukorambi Kabuapaten Jember. [Skripsi]. Jawa Timur: Fakultas Kedokteran, Jember, Jawa Timur.

WHO. (2020). Soil-Transmitted Helminth Infections. Tersedia: https://www.who.int/newsroom/fact-sheets/detail/soiltransmitted-helminth-infections [13 Oktober 2020]. 